\title{
An Effective Dose of Magnetic Field to Increase Sesame Plant Growth and Its Resistance to Fusarium oxysporum Wilt
}

\author{
Mokhamad Tirono $^{1 *}$, Farid Samsu Hananto ${ }^{1}$, Suhariningsih $^{2}$, Viranita Qurotul Aini ${ }^{1}$ \\ ${ }^{1}$ Physics Department, Faculty of Science and Technology, Universitas Islam Negeri Maulana Malik Ibrahim Malang, Malang \\ 65144, East Java, Indonesia \\ ${ }^{2}$ Physics Department, Faculty of Science and Technology, Airlangga University, Surabaya 60115, East Java, Indonesia
}

Corresponding Author Email: mokhtirono@uin-malang.ac.id

https://doi.org/10.18280/ijdne.160306

Received: 1 April 2021

Accepted: 8 June 2021

\section{Keywords:}

chlorophyll, emergence times, fruit, magnetic field, stem

\begin{abstract}
Globally, sesame consumption continues to increase, so it requires additional production to balance. Often there are obstacles in the production process, both technique and the presence of pests. One way to increase production is to treat it with a magnetic field during seed growth and germination. This study aims to determine the magnetic flux density (MFD) to obtain the optimal stem growth, chlorophyll content, fruit size, and plant resistance to Fusarium oxysporum. The seeds are processed by giving treatment using a MFD of 0.0-0.5 mT, which oscillates with a frequency of $50 \mathrm{~Hz}$. Plant seeds were treated using a magnetic field every day for five days with a treatment time of 20 minutes each. The results showed that sesame seeds treated with magnetic fields had earlier emergence time of sprouts, higher stems, more chlorophyll content, faster flowering, larger fruit sizes, and more resistance to $F$. oxysporum wilt attacks. Treatment with a MFD of $0.3 \mathrm{mT}$ resulted in optimal plant growth, health, and resistance to $F$. oxysporum attack. Treatment of seeds using magnetic fields ranging from wetting the seeds to germinating makes the plants healthier, bigger fruits, and more resistant to $F$. oxysporum wilt attacks.
\end{abstract}

\section{INTRODUCTION}

At present many studies are being carried out to determine the effect of magnetic fields on living organisms. Magnetic fields induce an electric potential that exerts cellular pressure, thereby causing changes in the biochemical, physical, and physiological structures and functions of cells in living systems [1]. Magnetic fields influence the activation of protein synthesis [2], cause changes at the cellular level [3], and increase cell viability, organization, and differentiation [4]. The application of magnetic fields in agriculture is a new, environmentally friendly technology to improve seed germination and increase yields by influencing physiological and biochemical processes in seed materials $[5,6]$. Treatment using magnetic fields during seeding and seed germination will affect cell-reproduction and metabolism [7], Deoxyribo Nucleic Acid [8], and enzyme activity [9]. Previous studies have reported that treatment using magnetic fields can accelerate the growth and enlargement of okra and eggplant fruit [10]. The MFD of $130 \mathrm{mT}$ increased shoot length and the chlorophyll content of lupine [11]. The MFD of $600 \mathrm{mT}$ affects root growth [12].

Sesame has essential nutrients for humans, either in the form of oil, paste, or mixed with other foods [13]. Consumption of sesame globally continues to increase mainly due to changes in consumption patterns and consumer awareness. Global sesame consumption was USD 6,559.0 million in 2018 and will reach USD 7,244.9 million by 2024 with a CAGR (compound annual growth rate) of $1.7 \%$ [14]. The problem is that sesame production in most areas is carried out traditionally, resulting in low crop production and productivity [15]. The presence of weeds, pests, and insect diseases, moisture stress during the nursery and growth stages causes a significant decrease in the yield and quality of the sesame [15]. Sesame plants are susceptible to biotic and abiotic stresses [16] and are prone to suffering from various diseases [17].

Previous studies have reported that growth and improved yield of lettuce can be accomplished by treating the seeds before they grow, using non-uniform sinusoidal magnetic fields [18]. The treatment of magnetic fields will change the properties of water, including surface tension and viscosity [19], so that the ability to soak the seeds increases [20]. Treatment using magnetic fields on seeds can prolong the life of free radical ions by inducing unpaired singlet-triplet electron transitions causing oxidative stress [21]. Oxidative stress is the main factor that increases mutations [1] in plant cells. The magnetic field has an effect on photochemical activity; for example, the absorption rate of $\mathrm{CO}_{2}$ in radish (Raphanus sativus L.) decreases after treatment to the magnetic field [22]. The chlorophyll content is an indicator of plant health and productivity [23].

Based on the results of previous research, the treatment of magnetic fields in sesame seeds is carried out when wetting them until they grow sprouts, making the sprouts appear and growing the plants faster, the plants healthier and more resistant to $F$. Oxysporum wilt. Treatment is carried out using a magnetic field that changes with time by varying the density of magnetic flux to obtain an effective dose to increase its growth and resistance to $F$. oxysporum wilt. Previous studies 
have not yet reported the effects of magnetic field treatment from wetting the seeds to germinating and revealed an effective dose to increase growth and resistance of $F$. oxysporum wilt.

This study aims to determine the effective dose of the magnetic field to accelerate the emergence time of sprouts and stem growth, increase the chlorophyll content of leaves, accelerate flowering time, and increase the fruit weight of the sesame plant both in conditions without infection or infection with $F$. oxysporum wilt.

\section{METHODOLOGY}

\subsection{Magnetic field generation}

The magnetic field used in the seed treatment comes from two Helmholtz coils arranged parallel so that the resulting MFD along the coil axis is [24]:

$$
\boldsymbol{B}=\frac{\mu_{o} N I}{2 R}\left(\left\lfloor 1+\left(\frac{x+\alpha / 2}{R^{2}}\right)^{2}\right\rfloor^{-3 / 2}+\left\lfloor 1+\left(\frac{x-\alpha / 2}{R^{2}}\right)^{2}\right\rfloor^{-3 / 2}\right)
$$

where, $N=$ Number of turns of the coil, $I=$ current flowing in the coil, $R=$ radius of coil, $\alpha=$ distance between the two coils, and $\mu_{0}=$ permeability of free space. The MFD at the center of the coil system $(x=0)$ is:

$$
\boldsymbol{B}=\frac{\mu_{o} N I}{R}\left\lfloor 1+\left(\frac{\alpha}{2 R}\right)^{2}\right\rfloor^{-3 / 2}
$$

The coil flows an electric current that meets the equation:

$$
I=I_{m} \sin (2 \pi f t+\varphi)
$$

where, $f=$ frequency, $I_{m}=$ maximum current, and $\varphi=$ phase angle. If the current flow has a frequency of $50 \mathrm{~Hz}$, the resulting electric field oscillates with a frequency of $50 \mathrm{~Hz}$.

Changes in MFD are carried out by changing the strength of the current flowing in the coil. The resulting MFD density was measured using the Kanetec TM801 Tesla Meter.

\subsection{Sample}

The research sample was the Winas 1 variety of sesame seeds, which is a great yielding variety of the early sesame from Indonesian Center for Estate Crops Research and Development. Sesame sizes are almost the same and weigh 45 milligrams of the seeds. The sample consisted of 12 groups, each group numbering ten seeds or replicates.

\subsection{Magnetic field treatment}

Perform seed treatment starting from wetting with water to germination. The position of the seed stalk is arranged in the direction of the magnetic force line. The direction of the magnetic field is set parallel to the direction of the earth's magnetic field. Treatment of seeds using a magnetic field was carried out at a room temperature of $27^{\circ} \mathrm{C}$. The treatment used a MFD of $0.0-0.5 \mathrm{mT}$, treatment time of 20 minutes per day, and implementation of 5 days. The treatment time of 20 minutes makes the effect of changing water and seed temperature negligible. The flow of alternating current in the coil makes the impedance of the coil increase, resulting in a change in electrical energy into heat energy. Previous studies reported that treatment with a MFD of $1.2-3.75 \mathrm{mT}$, a frequency of $20 \mathrm{~Hz}$, and a treatment time of 5-40 minutes on the water caused a significant temperature increase when the treatment time was 33-37 minutes [25]. Excess heat has the potential to damage the seeds that are being grown.

\subsection{Planting}

Seven days after the completion of the treatment, the grown sesame seeds were planted in polybags. The size of the Polybag used is $30 \mathrm{~cm}$ in diameter and $20 \mathrm{~cm}$ in height. Before planting, polybags filled with pure soil without fertilizer with $\mathrm{pH}$ 7.0. The temperature of the environment where planting is $23-29^{\circ} \mathrm{C}$, while the humidity is $80-85 \%$. The plants in the Polybag are watered once a day and done in the morning. Watering is done with a water volume of $25 \mathrm{~mL}$ at 1-14 days old and $240 \mathrm{~mL}$ when the plants are more than 14 days old for one plant. Plants were given NPK fertilizer with the same size for each sample when they were 10, 20,30, and 40 days after planting in polybags. The fertilizer weights were $3,5,6$, and 6 grams of each plant, respectively. After the plant is 30 days old, then $10^{7}$ conidia/mL of $F$. oxysporum are injected into the plant stems. Plants injected with $F$. oxysporum were one group from each group treated with a MFD of 0.0-0.5 mT.

\subsection{Measurement}

Calculation of the emergence time of sprouts starts from wetting the seeds. When the plants are 7, 21, 35, and 49 days after being transferred to polybags, the stems' height is measured. Measurement of chlorophyll content was carried out based on Mackinney's work and measured the absorbance using a UV-Vis Spectrophotometer [26]. Chlorophyll contents were measured when the plants were 58 days old, namely on the third leaf from the bottom. The absorbance measurements were carried out at $645 \mathrm{~nm}$ and $663 \mathrm{~nm}$ wavelengths of light. Flowering age is calculated from the time of planting in polybags until the beginning of flower buds. Weighing the weight of the fruit is done when the size of the fruit does not have changed. Weighing the fruit's weight is done when the fruit is still fresh, that is, immediately after picking.

\section{RESULTS AND DISCUSSION}

\subsection{Emergence time of sprouts}

Figure 1 is a graph of the emergence time of the sesame seeds treated with a MFD of $0.0-0.5 \mathrm{mT}$. The graph shows that treatment using a magnetic field during seed wetting will shorten the emergence time of sprouts from $2.97 \pm 0.04$ days to $2.44 \pm 0.14$ days when given a magnetic field with a MFD of $0.1 \mathrm{mT}$. The shortest emergence time of sprouts occurred in the seeds treated with a MFD of $0.3 \mathrm{mT}$, namely $2.23 \pm 0.19$ days. Treatment with a MFD of 0.4 and $0.5 \mathrm{mT}$ made the emergence time of sprouts longer than treatment with a MFD of $0.3 \mathrm{mT}$. The statistical test showed that the treatment using a magnetic field had a significant effect on the emergence time of sprouts $(\mathrm{p} \leq 0.05)$. 


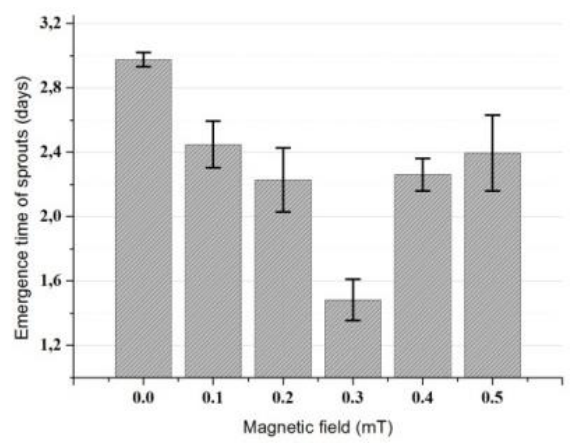

Figure 1. Emergence time of sprouts

\subsection{Stem height}

Table 1 is the sesame stem height data after 7, 21, 35, 49 days and treated with a MFD of $0.0-0.5 \mathrm{mT}$. Sesame stem was treated with a higher magnetic field than without treatment, where the height of the stems at the age of 7.0 days was $4.31 \pm 0.49 \mathrm{~cm}$ (with a MFD of $0.1 \mathrm{mT}$ ) and $3.95 \pm 0.03 \mathrm{~cm}$, respectively. Optimum stem height when treated with a MFD of $0.3 \mathrm{mT}$, namely $5.59 \pm 0.38 \mathrm{~cm}$ and $93.6 \pm 4.10 \mathrm{~cm}$ at the age of 7 and 49 days, respectively. The percentage difference in the height of the bar at 49 days between the untreated and treated with a $0.3 \mathrm{mT}$ magnetic field is $10.77 \%$. Thus, in general, seeds treated with magnetic fields had higher stems than untreated seeds.

Table 1. Sesame plant height after 7, 21, 35, and 49 days

\begin{tabular}{ccccc}
\hline $\begin{array}{c}\text { Magnetic } \\
\text { Field } \\
(\mathbf{m T})\end{array}$ & \multicolumn{4}{c}{$\begin{array}{c}\text { Stem height } \\
\text { at age (days) }\end{array}$} \\
\cline { 2 - 5 } & $\mathbf{7}$ & $\mathbf{2 1}$ & $\mathbf{3 5}$ & $\mathbf{4 9}$ \\
\hline 0 & $3.95 \pm 0.03$ & $13.74 \pm 0.77$ & $39.50 \pm 1.22$ & $84.50 \pm 1.27$ \\
0.1 & $4.31 \pm 0.49$ & $14.74 \pm 0.51$ & $44.90 \pm 1.92$ & $84.80 \pm 2.82$ \\
0.2 & $4.78 \pm 0.34$ & $15.23 \pm 0.77$ & $46.10 \pm 2.16$ & $91.30 \pm 3.96$ \\
0.3 & $5.59 \pm 0.38$ & $16.29 \pm 0.61$ & $48.80 \pm 2.20$ & $93.60 \pm 4.10$ \\
0.4 & $4.42 \pm 0.24$ & $14.58 \pm 0.45$ & $42.60 \pm 2.95$ & $89.10 \pm 2.07$ \\
0.5 & $4.12 \pm 0.85$ & $14.11 \pm 0.68$ & $41.50 \pm 2.09$ & $86.50 \pm 4.00$ \\
\hline
\end{tabular}

Table 2. Sesame plant height after 7, 21, 35, and 49 days infected with F.oxysporum

\begin{tabular}{ccccc}
\hline \multirow{2}{*}{$\begin{array}{c}\text { Magnetic } \\
\text { Field } \\
(\mathbf{m T})\end{array}$} & \multicolumn{4}{c}{$\begin{array}{c}\text { Stem height } \\
\text { at age (days) }\end{array}$} \\
\cline { 2 - 5 } & $\mathbf{7}$ & $\mathbf{2 1}$ & $\mathbf{3 5}$ & $\mathbf{4 9}$ \\
\hline 0 & $3.92 \pm 0.33$ & $13.83 \pm 0.37$ & $32.30 \pm 2.39$ & $37.10 \pm 9.05$ \\
0.1 & $4.38 \pm 0.27$ & $14.77 \pm 1.12$ & $34.00 \pm 2.09$ & $43.60 \pm 6.11$ \\
0.2 & $4.74 \pm 0.42$ & $15.28 \pm 0.63$ & $35.50 \pm 2.37$ & $49.10 \pm 9.67$ \\
0.3 & $5.56 \pm 0.74$ & $16.25 \pm 0.65$ & $41.40 \pm 1.39$ & $68.70 \pm 6.20$ \\
0.4 & $4.49 \pm 0.33$ & $14.53 \pm 0.34$ & $33.90 \pm 1.43$ & $47.60 \pm 4.48$ \\
0.5 & $4.15 \pm 0.29$ & $14.17 \pm 0.47$ & $32.80 \pm 1.52$ & $42.90 \pm 7.84$ \\
\hline
\end{tabular}

This condition is thought to be caused by changes in DNA. Where treatment of magnetic fields increases deoxyribonucleic acid (DNA) repair [27]. Magnetic fields influence DNA and RNA synthesis [28]. Magnetic fields in the very low frequency (ELF) and radiofrequency (RF) ranges activate the cellular stress response, inducing protection of stress response genes [29]. The effect of magnetic field treatment on DNA is influenced by MFD and treatment time, so that each MFD has a different effect. Treatment with a MFD of $0.5 \mathrm{mT}$, a frequency of $50 \mathrm{~Hz}$ for 2 hours in 5 days will cause DNA degradation [30]. Fourteen days of exposure to magnetic fields had the potential to cause DNA damage, but none was found in the 2 hours and 5-day exposures [31].

DNA changes due to treatment using magnetic fields make sesame plants more resistant to pests, especially $F$. oxysporum. One form of resistance is shown by the stems of plants that grow taller than those without magnetic field treatment. Table 2 shows that the height of the plant stems without magnetic field treatment at the age of 49 days is $37.1 \pm 9.05 \mathrm{~cm}$, while with a $0.1 \mathrm{mT}$ magnetic field treatment is $43.6 \pm 6.11 \mathrm{~cm}$. The treatment with a MFD of $0.3 \mathrm{mT}$ obtained the optimum stem height of $68.7 \pm 6.20 \mathrm{~cm}$ and gradually lower in the treatment with a MFD of $0.4 \mathrm{mT}$ and $0.5 \mathrm{mT}$. Treatment using a magnetic field made the stems of plants able to grow from 42 days to 49 days, while those that were not treated were getting shorter in size because the plants wilted.

\subsection{Chlorophyll content}

Figure 2 is the content of chlorophyll- $a$ and chlorophyll- $b$ of sesame leaves at 58 days. The highest chlorophyll content was obtained from plants treated with a magnetic flux density of $0.3 \mathrm{mT}$, where the chlorophyll- $a$ content was $10.79 \pm 0.39$ $\mathrm{mg} / \mathrm{L}$ and chlorophyll- $b$ was $4.56 \pm 0.33 \mathrm{mg} / \mathrm{L}$. The lowest chlorophyll content was obtained from plants that were not

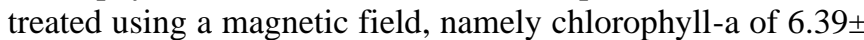
$0.23 \mathrm{mg} / \mathrm{L}$ and chlorophyll-b of $0.65 \pm 0.21 \mathrm{mg} / \mathrm{L}$. Overall, the chlorophyll content of sesame leaves in plants treated with a MFD of 0.1-0.5 mT was higher than in untreated plants. Therefore, treatment with a MFD of 0.1-0.5 mT and a frequency of $50 \mathrm{~Hz}$ has a significant effect on the chlorophyll content in the leaves of sesame plants $(p \leq 0.05)$. This condition occurs because the magnetic field can increase the energy in distributing the atoms, causing the acceleration of metabolism [23]. The increased ion mobility and ion absorption due to the magnetic field treatment resulted in better growth stimulation. This condition makes it easier for plants to carry out photosynthesis [32].

The magnetic field treatment increased the chlorophyll content of sesame plants infected with $F$. oxysporum. Figure 3. is data on the chlorophyll content of sesame leaves infected with $F$. oxysporum at 30 days. The highest chlorophyll content was found in plants treated with a MFD of $0.3 \mathrm{mT}$, chlorophyll- $a$ of $8.06 \pm 0.19 \mathrm{mg} / \mathrm{L}$, and chlorophyll- $b$ of $3.16 \pm 0.07 \mathrm{mg} / \mathrm{L}$. The chlorophyll content decreased again after being treated with a MFD of $0.4 \mathrm{mT}$ and $0.5 \mathrm{mT}$. The results of statistical tests showed that the magnetic field treatment had a significant effect on the chlorophyll content of sesame leaves infected with $F$. Oxysporum ( $\leq 0.05)$.

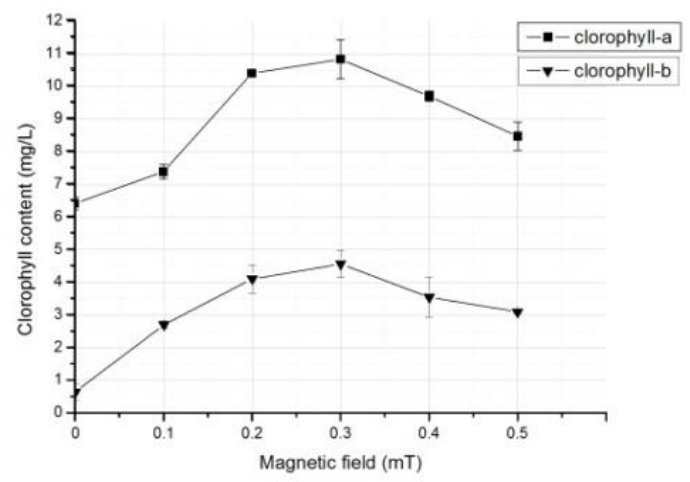

Figure 2. Chlorophyll content without $F$. oxysporum infection 


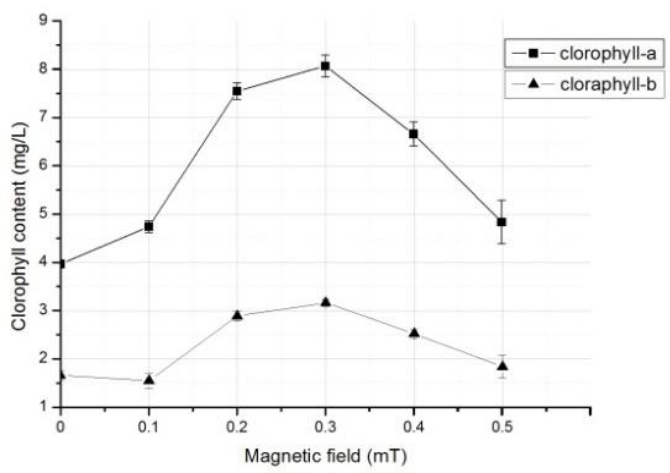

Figure 3. Chlorophyll content with $F$. oxysporum

\subsection{Flowering age}

Magnetic field treatment can accelerate plant metabolism, thereby accelerating the flowering start time compared to untreated plants, as shown in Figure 4. The fastest flowering time was the plants treated with a MFD of $0.3 \mathrm{mT}$, namely at the age of $51.4 \pm 0.55$ days, whereas without treatment, flowering began at the age of $54 \pm 1.22$ days. Statistical analysis showed that magnetic field treatment had a significant effect on flowering time with $\mathrm{p} \leq 0.05$. The same condition occurred in plants infected with $F$. oxysporum, where the flowering time of plants treated with magnetic fields was faster than those that were not treated, as shown in Figure 5. However, the difference in flowering time was not significant, except for plants treated with a MFD of $0.3 \mathrm{mT}$, where the plants flowered at the age of $52 \pm 0.71$ days. whereas without treatment to flowering at $54 \pm 1.00$ days. Plant infection with $F$. oxysporum does not affect the flowering time of the sesame plant but affects the number and freshness of the flowers.

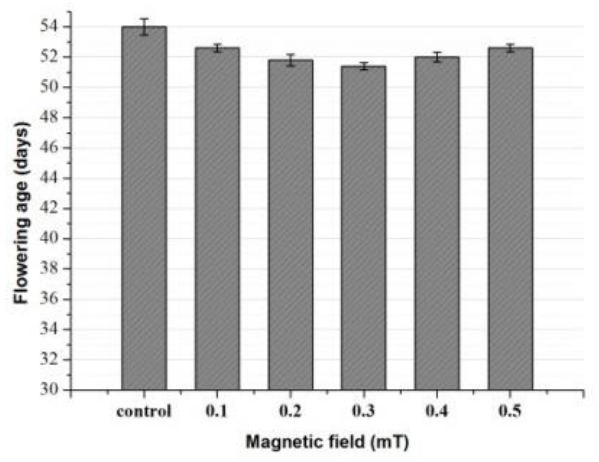

Figure 4. Time to start flowering without $F$. oxysporum infection

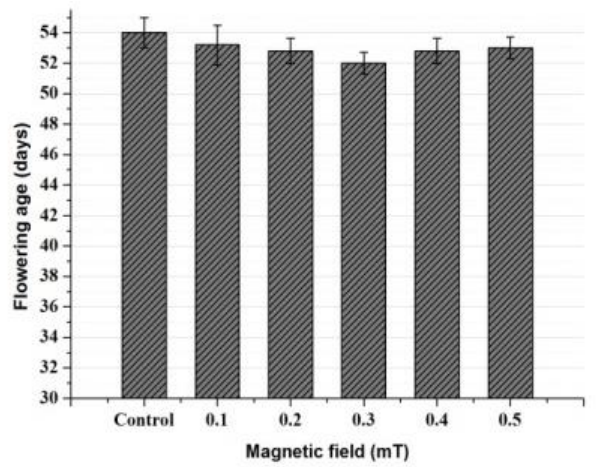

Figure 5. Time to start flowering with $F$. oxysporum infection

\subsection{Fruit weight}

The fruit is picked from the tree when the fruit does not change in size. The fruit is weighed immediately after being picked from the tree or fresh. Figure 6 is a graph of the weight of the sesame fruit per seed treated with magnetic fields and without being treated. The weight of the sesame fruit treated with a MFD of 0.1- $0.5 \mathrm{mT}$ is heavier than the untreated ones. The untreated fruit weight was $1.37 \pm 0.10$ grams, while the fruit treated with a MFD of $0.1 \mathrm{mT}$ was $1.64 \pm 0.08$ grams. Plants treated with a MFD of $0.3 \mathrm{mT}$ weight $2.55 \pm 0.14$ grams or 1.86 times the weight compared to those not treated using a magnetic field. The results of statistical analysis showed a significant difference in fruit weight between plants without magnetic field treatment and those that were treated $(\mathrm{p} \leq 0.05)$.

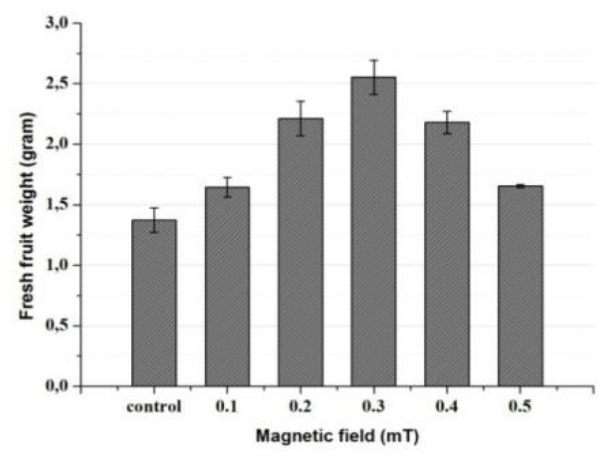

Figure 6. Fruit weight without $F$. oxysporum infection

F.oxysporum infection makes sesame plant growth disturbed, thus disturbing the weight of the fruit produced. Magnetic field treatment makes sesame plants more able to withstand pests so that the fruit weight is higher than untreated plants, as shown in Figure 7. Treatment with a MFD of 0.1, 0.4 , and $0.5 \mathrm{mT}$ did not significantly affect the weight of the sesame fruit infected with $F$. oxysporum. Meanwhile, those treated with a MFD of $0.2 \mathrm{mT}$ and $0.3 \mathrm{mT}$ had a significant effect ( $\mathrm{p} \leq 0.05)$. In the treatment with a MFD of $0.3 \mathrm{mT}$, the optimum fruit weight was $0.77 \pm 0.10$ grams, while the untreated plants had a fruit weight of 0.36 grams.

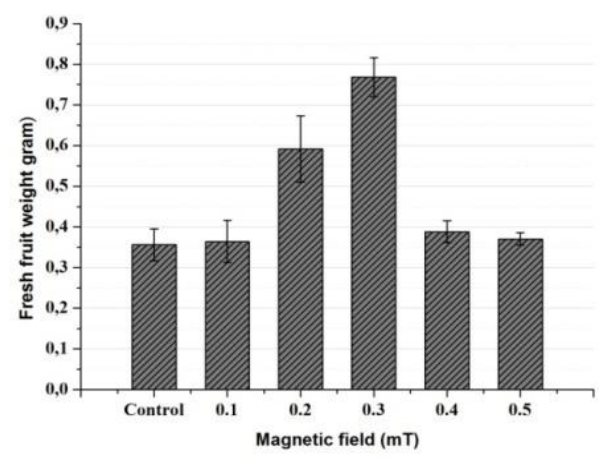

Figure 7. Fruit weight of plants infected with the pathogen $F$. oxysporum

\subsection{Discussion}

In this study, treatment with a MFD from $0.1 \mathrm{mT}$ to $0.3 \mathrm{mT}$ made the sprouts grow faster, increased stem height, more chlorophyll content, shorter flowering time, heavier fruit weight, and resistance to $F$. oxysporum increased compared to 
control. Treatment with a MFD of $0.4-0.5 \mathrm{mT}$ began to decrease compared to treatment with $0.3 \mathrm{mT}$. Therefore, treatment with a MFD of $0.3 \mathrm{mT}$ provided optimal plant growth and resistance to $F$. oxysporum. Treatment with magnetic fields on seeds immersed in water causes shifting and polarization of the water atoms, thereby changing the physicochemical properties of water, including decreasing surface tension and increasing its viscosity [19]. The magnetic field treatment on the seeds causes the enzyme activity in the embryo to increase [33]. The interaction force of the magnetic field with seed and water can be expressed by [34]:

$$
\Delta F=\Delta \varkappa_{0} \mathrm{~V} H \nabla H
$$

where, $\Delta x_{0}$ is the change in the magnetic susceptibility of water or material, $V$ is the volume of the material, $H$ is the magnetic field, and $\nabla H$ is the magnitude of the magnetic field gradient.

Eq. (4) shows that the magnetic field interaction force is influenced by the magnetic field intensity $(H)$ and the change in the magnetic field $\nabla H$. Therefore, water can immerse the seeds with changes in density due to exposure to magnetic fields. Previous studies reported that changes in the relative water mass uptake by seeds increased from 0.7 to 0.79 with a stationary magnetic field treatment of $0-10 \mathrm{mT}$ for 8 hours [35]. Treatment using magnetic fields makes it easier for the planted seeds to absorb water [36]. The emergence time of each of the respective magnetic flux densities is different, whereas increasing the moisture pressure progressively inhibits seed germination [37].

In this study, the magnetic field oscillates with a frequency of $50 \mathrm{~Hz}$, so a low MFD is required for seed treatment. Changing magnetic fields are a solution for using low magnetic flux densities [38]. Previous studies have reported that treatment using a MFD of $150 \mathrm{mT}$ for 72 hours can shorten the emergence time of potato seed sprouts from 31.8 days to 14.0 days [39].

After the sprouts have grown, the magnetic field treatment can prolong the life of the free radical ions by inducing unpaired electron-triplet transitions that cause oxidative stress [21, 33], which affects cell reproduction, cellular metabolism, gene expression, and enzyme activity [40]. This condition makes the plant stems grow faster so that the sesame plant stems are treated with a higher magnetic field than without being treated. Previous studies reported that treatment with a MFD of 0.33 T increased plant height from $4.18 \mathrm{~cm}$ to $5.25 \mathrm{~cm}$ at four weeks of age [41]. Differences in stem height between plants treated with magnetic fields and without treatment also occurred in plants infected with $F$. oxysporum. Magnetic field treatment increases the occurrence of chemical reactions that positively affect plant photochemical activity, respiration ratio, and enzyme activity [21]. Previous studies have reported that static magnetic field treatment with a magnetic flux density of $50 \mathrm{mT}$ increased chlorophyll content, while $100 \mathrm{mT}$ tended to decrease [42]. Identical reports suggest that magnetic fields significantly enhance all photosynthetic pigments [43]. The chlorophyll content is closely related to plant health, where the higher the chlorophyll content, the better the plant health [44]. Therefore, the plants treated with the magnetic field could withstand $F$. oxysporum wilt better than the untreated ones. This is indicated by higher plant stems, more chlorophyll content, faster flowering time, heavier fruit weight.

Magnetic fields have a very high stimulatory effect on cell multiplication, growth, and development [6], thus triggering faster flowering. Several studies have reported that magnetic field treatment affects productivity [45-47]. This study also showed that the fruit weight produced from plants treated with a magnetic field was higher than that of untreated plants.

In this study, a lower magnetic field and shorter maintenance time are required compared to using a static electric field. The magnetic flux density that resulted in optimum growth and resistance to $F$. oxysporum was $0.3 \mathrm{mT}$. The drawback is that connecting the Helmholtz coil with a sinusoidal electric current increases the impedance so that the temperature of the coil increases.

\section{CONCLUSION}

Magnetic field treatment with changing treatment times and a frequency of $50 \mathrm{~Hz}$ during seed wetting and germination were effective in accelerating the emergence of sprouts, accelerating growth, improving sesame plant health, and making plants more resistant to $F$. oxysporum wilt. The effective dose was obtained in the treatment with a magnetic flux density of $0.3 \mathrm{mT}$ with a treatment duration of 20 minutes every day for five days. Research has not revealed the use of other magnetic field frequencies, their significance for the total productivity and quality of the sesame yield, and their application to other types of crops. Therefore, further research is still needed.

\section{ACKNOWLEDGMENT}

This research was carried out on the financial assistance from the Directorate of Islamic Higher eEucation, Indonesian Ministry of Religious Affairs. Therefore, we thank the Minister of Religious Affairs along with his staff. We also thank the research and community service institution of State Islamic Universities of Maulana Malik Ibrahim Malang.

\section{REFERENCES}

[1] Dhawi, F., Al-Khayri, J.M. (2008). Proline accumulation in response to magnetic fields in date palm (Phoenix dactylifera L.). The Open Agriculture Journal, 2(1): 8083. https://doi.10.2174/187433150080 2010080

[2] Nakasono, S., Saiki, H. (2000). Effect of ELF magnetic fields on protein synthesis in Escherichia coli K12. Radiation Research, 154(2): 208-216. https://doi.org/10.1667/00337587

[3] Zablotskii, V., Polyakova, T., Lunov, O., Dejneka, A. (2016). How a high-gradient magnetic field could affect cell life. Scientific Report, 6: 1-13. https://doi.org/10.1038/srep37407

[4] Valiron, O., Peris, L., Rikken, G., Schweitzer, A., Saoudi, Y., Remy, C., Job D. (2005). Cellular disorders induced by high magnetic fields. Journal of Magnetic Resonance Imaging, 22(3): https://doi.org/10.1002/jmri.20398

[5] El-Gizawy, A.M., Ragab, M.E. Helal, N.A.S., El-Satar, A., Osman, I.H. (2016). Effect of magnetic field treatments on germination of true potato seeds, seedlings growth and potato tubers characteristics. Middle East Journal of Agriculture Research, 5(1): 74-81. http://www.curresweb. com/mejar/mejar/2016/74-81 
[6] Maffei, M.E. (2014). Magnetic field effects on plant growth, development, and evolution. Frontiers in Plant Science, 5:

$1-15$. https://doi.org/10.3389/fpls.2014.00445

[7] Çelik, Ö., Atak, Ç., Rzakulieva, A. (2008). Stimulation of rapid regeneration by a magnetic field in Paulownia node cultures. Journal of Central European Agriculture, 9(2): 297-303. https://doi.org/10.5513/jcea.v9i2.670

[8] Yang, X., Li, Z., Polyakova T., Dejneka, A., Zablotskii, V., Zhang, X. (2020). Effect of static magnetic field on DNA synthesis: The interplay between DNA chirality and magnetic field left-right asymmetry. FASEB BioAdvances, 2(4): 254-263. https://doi.org/10.1096/fba.2019-00045

[9] Atak, C., Çelik, O., Olgun, A., Alikamanoğlu, S., Rzakoulieva, A. (2007). Effect of magnetic field on peroxidase activities of soybean tissue culture. Biotechnology \& Biotechnological Equipment, 21(2): 166-171. https://doi.org/10.1080/13102818.2007.10817438

[10] Rio, L.C., Rio, M.M. (2013). Effect of electro-magnetic field on the growth characteristics of okra (Abelmoschus Esculentus), tomato (Solanum Lycopersicum) and eggplant (Solanum Melongena). International Journal of Scientific and Research Publications, 3(10): 1-9.

[11] Mroczek-Zdyrska, M., Kornarzyński, K., Pietruszewski, S., Gagoś, M. (2016). Stimulation with a 130-mT magnetic field improves growth and biochemical parameters in lupin (Lupinus angustifolius 1.). Turkish Journal of Biology, 40(3): 699-705. https://doi.org/10.3906/biy-1504-19

[12] Jin, Y., Guo, W., Hu, X. et al. (2019). Static magnetic field regulates Arabidopsis root growth via auxin signaling. Scientific Reports, 9(1): 1-14. https://doi.org/10.1038/s41598-019-50970-y

[13] Elleuch, M., Besbes, S., Roiseux, O., Blecker, C., Attia, H. (2007). Quality characteristics of sesame seeds and by-products. Food Chemistry, 103(2): 641-650. https://doi.org/10.1016/j.foodchem.2006.09.008

[14] Myint, D., Gilani, S.A., Kawase, M., Watanabe, K.N. (2020). Sustainable sesame (Sesamum indicum L.) production through improved technology: An overview of production, challenges, and opportunities in Myanmar. Sustainability, 12(9): 1-21. https://doi.org/10.3390/SU12093515

[15] Girmay, A.B. (2018). Sesame production, challenges and opportunities in Ethiopia. Vegetos-An International Journal of Plant Research \& Biotechnology, 31(1): 5156. https://doi.org/ 10.5958/2229-4473.2018.00007.1

[16] Rehman, I., Deeba, F., ul Haque, M.I., Naqvi, S.M.S. (2013). Inhibition of sesame seedling growth by Xanthomonas campestris PV. Sesami culture secretions. The Journal of Animal \& Plant Science, 23(4): 12071210.

[17] Ojiambo, P.S., Mibey, R.K., Narla, R.D., Ayiecho, P.O. (2003). Field transmission efficiency of Alternaria sesami in sesame from infected seed. Crop Protection, 22(9): 1107-1115. https://doi.org/10.1016/S02612194(03)00144-3

[18] De Souza, A., Sueiro, L., González, L.M., Licea, L., Porras, E.P., Gilart, F. (2008). Improvement of the growth and yield of lettuce plants by non-uniform magnetic fields. Electromagnetic Biology and Medicine. 27(2):

$173-184$ https://doi.org/10.1080/15368370802118605

[19] Cai, R., Yang, H., He, J., Zhu, W. (2009). The effects of magnetic fields on water molecular hydrogen bonds. Journal of Molecular Structure Journal, 938(1-3): 15-19. https://doi.org/10.1016/j.molstruc.2009.08.037

[20] Pang, X.F., Bo, D. (2008). The changes of macroscopic features and microscopic structures of water under influence of magnetic field. Physica B, 403(19-20): 3571-3577. https://doi.org/10.1016/j.physb.2008.05.032

[21] Sahebjamei, H., Abdolmaleki, P., Ghanati, F. (2007). Effects of magnetic field on the antioxidant enzyme activities of suspension-cultured tobacco cells. Bioelectromagnetics, 28(1): 42-47. https://doi.org/10.1002/bem.20262

[22] Yano, A., Ohashi, Y., Hirasaki, T., Fujiwara, K. (2004). Effects of a $60 \mathrm{~Hz}$ magnetic field on photosynthetic $\mathrm{CO}_{2}$ uptake and early growth of radish seedlings. Bioelectromagnetics, 25(8): 572-581. https://doi.org/10.1002/bem.20036

[23] Dhawi F., Al-Khayri, J.M. (2009). Magnetic fields induce changes in photosynthetic pigments content in date palm (Phoenix dactylifera L.) seedlings. The Open Agriculture Journal, 3(1): 1-5. https://doi.org/10.2174/1874331500903010001

[24] Bhatt, V., Rautela, R., Sharma, P., Tiwari, D., Khushu, S. (2010). Design \& Development of Helmholtz Coil for Hyperpolarized MRI. Excerpt from Proc COMSOL Conf $2010 \quad$ India, [Online]. https://www.comsol.com/paper/download/62250/bhatt_ paper.pdf.

[25] Ayrapetyan, S.N., Amyan, A.M., Ayrapetyan, G.S. (2006). The effects of static magnetic fields, low frequency electromagnetic fields and mechanical vibration on some physicochemical properties of water. Water and the Cell, 151-164. https://doi.org/10.1007/14020-4927-7

[26] Shibghatallah, M.A.H., Khotimah, S.N., Suhandono, S., Viridi, S., Kesuma, T. (2013). Measuring leaf chlorophyll concentration from its color: A way in monitoring environment change to plantations. AIP Conference Proceedings, 1554(1): 210-213. https://doi.org/10.1063/1.4820322

[27] Chow, K.C., Tung, W.L. (2000). Magnetic field exposure enhances DNA repair through the induction of DnaK/J synthesis. FEBS Letters, 478(1-2): 133-136. https://doi.org/10.1016/S0014-5793(00)01822-6

[28] Shabrangi, A., Majd, A., Sheidai, M. (2011). Effects of extremely low frequency electromagnetic fields on growth, cytogenetic, protein content and antioxidant system of Zea mays L. African Journal of Biotechnology, 10(46): 9362-9369. https://doi.org/10.5897/ajb11.097

[29] Ruediger, H.W. (2009). Genotoxic effects of radiofrequency electromagnetic fields. Pathophysiology, 16(2-3): 89-102. https://doi.org/10.1016/j.pathophys.2008.11.004

[30] Zendehdel, R., Yu, I.J., Hajipour-Verdom, B., Panjali Z. (2019). DNA effects of low level occupational exposure to extremely low frequency electromagnetic fields (50/60 $\mathrm{Hz}$ ). Toxicol Ind Health, 35(6): 424-430. https://doi.org/10.1177/0748233719851697

[31] Havas, M. (2017). When theory and observation collide: Can non-ionizing radiation cause cancer? Environ Pollution, 221: 501-505. https://doi.org/10.1016/j.envpol.2016.10.018 
[32] Hailemichael, G., Catalina, A., González, M.R., Martin, P. (2016). Relationships between water status, leaf chlorophyll content and photosynthetic performance in Tempranillo vineyards. South African Journal of Enology and Viticulture, 37(2): 149-156. https://doi.org/10.21548/37-2-1004

[33] Júnior, R.A.B., de Azevedo, R.L, Guimarães, R.M., Reis, L.V. (2020). Magnetic field in coffee seed germination. Cience Agrotecnologia, 44: 1-10. https://doi.org/10.1590/1413-7054202044003920

[34] Tao, Q., Zhang, L., Han, X., Chen, H., Ji, X., Zhang, X. (2020). Magnetic susceptibility difference-induced nucleus positioning in gradient ultrahigh magnetic field. Biophysical Journal, 118(3): 578-585. https://doi.org/10.1016/j.bpj.2019.12.020

[35] Reina, F.G., Pascual, L.A., Fundora, I.A. (2001). Influence of a stationary magnetic field on water relations in lettuce seeds. Part II: Experimental results. Bioelectromagnetics, 22(8): 596-602. https://doi.org/10.1002/bem.89

[36] da Silva J.A.T., Dobránszki, J. (2014). Impact of magnetic water on plant growth. Environmental and Experimental Biology, 12(4): 137-142.

[37] Maraghni, M. Gorai, M., Neffati, M. (2010). Seed germination at different temperatures and water stress levels, and seedling emergence from different depths of Ziziphus lotus. South African Journal of Botany, 76(3): 453-459. https://doi.org/10.1016/j.sajb.2010.02.092

[38] Zaidi, N.S., Sohaili, J., Muda, K., Sillanpää, M. (2014). Magnetic field application and its potential in water and wastewater treatment systems. Separation and Purification Reviews, 43(3): 206-240. https://doi.org/10.1080/15422119.2013.794148

[39] Bahadir, A., Sahin, N.K., Beyaz, R., Yildiz, M. (2020). Magnetic field effect on breaking tuber dormancy, early sprouting, seedling growth, and tuber formation in potato
(Solanum tuberosum L.). ScienceAsia, 46(5): 619. https://doi.org/10.2306/scienceasia 1513-1874.2020.077

[40] Belyavskaya, N.A. (2004). Biological effects due to weak magnetic field on plants. Advances in Space Research, 34(7): 1566-1574. https://doi.org/10.1016/j.asr.2004.01.021

[41] Fu, E. (2012). The effects of magnetic fields on plant growth and health. Young Scientists Journal, 11: 38-43. https://doi.org/10.4103/0974-6102.97696

[42] Răcuciu, M., Creangă, D., Horga, I. (2008). Plant growth under static magnetic field influence. Rom Reports Phys, 53(1-2): 353-359.

[43] Babaloo, F., Majd, A., Arbabian, S., Sharifnia, F., Ghanati, F. (2018). The effect of magnetized water on some characteristics of growth and chemical constituent in rice (Oryza sativa L.) Var Hashemi. EurAsian Journal of BioSciences, 12(1): 129-137.

[44] Pavlovic, D., Nikolic, B., Djurovic, S., Waisi, H., Andjelkovic, A., Marisavljevic, D. (2014). Chlorophyll as a measure of plant health: Agroecological aspects. Pestic ifitomedicina, 29(1): 21-34. https://doi.org/10.2298/pif1401021p

[45] Jamil, Y., Ul Haq, Z., Iqbal, M., Perveen, T., Amin, N. (2012). Enhancement in growth and yield of mushroom using magnetic field treatment. International Agrophysics, 26(4): 375-380. https://doi.org/10.2478/v10247-012-0052-4

[46] Aladjadjiyan, A. (2002). Study of the influence of magnetic field on some biological characteristics of Zea mais. Journal of Central European Agriculture, 3(2): 8994. https://core.ac.uk/download/pdf/25804486.pdf.

[47] Dardeniz, A., Tayyar, Ş., Yalçin, S. (2007). Influence of low-frequency electromagnetic field on the vegetative growth of grape cv. uslu. Journal of Central European Agriculture, 7(3): 389-396. 